\section{BRAZIULIAN JOURNAL}

OF MEDICAL AND BIOLOGICAL RESH ARCH

www.bjournal.com.br
ISSN 0100-879X

Volume 43 (01) 1-123 January 2010

BIOMEDICAL SCIENCES

AND

CLINICAL INVESTIGATION

Braz J Med Biol Res, J anuary 2010, Volume 43(1) 25-35

Expression of beta 2 integrin (CD18) in embryonic mouse and chicken heart

L.A.M. Oliveira, R.K. Baker, S.E. Klewer and G.T. Kitten

The Brazilian Journal of Medical and Biological Research is partially financed by
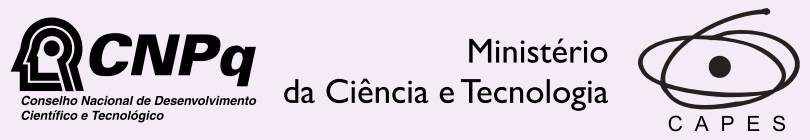

Ministério da Educação

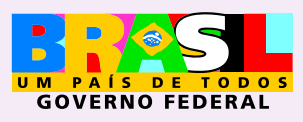

Institutional S ponsors 


\title{
Expression of beta 2 integrin (CD18) in embryonic mouse and chicken heart
}

\author{
L.A.M. Oliveira ${ }^{1}$, R.K. Baker ${ }^{2}$, S.E. Klewer ${ }^{3}$ and G.T. Kitten ${ }^{1}$ \\ ${ }^{1}$ Departamento de Morfologia, Instituto de Ciências Biológicas, \\ Universidade Federal de Minas Gerais, Belo Horizonte, MG, Brasil \\ 2Departments of Cell Biology and Anatomy, \\ ${ }^{3}$ Department of Pediatrics, Steele Children's Research Center, \\ University of Arizona School of Medicine, Tucson, AZ, USA
}

\begin{abstract}
Integrins are heterodimeric receptors composed of $\alpha$ and $\beta$ transmembrane subunits that mediate attachment of cells to the extracellular matrix and counter-ligands such as ICAM-1 on adjacent cells. $\beta 2$ integrin (CD18) associates with four different $\alpha$ (CD11) subunits to form an integrin subfamily, which has been reported to be expressed exclusively on leukocytes. However, recent studies indicate that $\beta 2$ integrin is also expressed by other types of cells. Since the gene for $\beta 2$ integrin is located in the region of human chromosome 21 associated with congenital heart defects, we postulated that it may be expressed in the developing heart. Here, we show the results from several different techniques used to test this hypothesis. PCR analyses indicated that $\beta 2$ integrin and the $\alpha \mathrm{L}, \alpha \mathrm{M}$, and $\alpha \mathrm{X}$ subunits are expressed during heart development. Immunohistochemical studies in both embryonic mouse and chicken hearts, using antibodies directed against the $\mathrm{N}$ - or $\mathrm{C}$-terminal of $\beta 2$ integrin or against its $\alpha$ subunit partners, showed that $\beta 2$ integrin, as well as the $\alpha \mathrm{L}, \alpha \mathrm{M}$, and $\alpha \mathrm{X}$ subunits, are expressed by the endothelial and mesenchymal cells of the atrioventricular canal and in the epicardium and myocardium during cardiogenesis. In situ hybridization studies further confirmed the presence of $\beta 2$ integrin in these various locations in the embryonic heart. These results indicate that the $\beta 2$ integrin subfamily may have other activities in addition to leukocyte adhesion, such as modulating the migration and differentiation of cells during the morphogenesis of the cardiac valves and myocardial walls of the heart.
\end{abstract}

Key words: Beta 2 integrin; CD18; Cardiac development; Epithelial-mesenchymal transformation; Down syndrome; Mouse and chicken cardiogenesis

\section{Introduction}

Integrins are transmembrane protein receptors that mediate cell-matrix and cell-cell adhesion. They consist of non-covalently linked heterodimers, which are composed of alpha $(\alpha)$ and beta $(\beta)$ subunits (1). To date, $18 \alpha$ and $8 \beta$ subunits have been characterized and shown to assemble into at least 24 distinct integrin heterodimers in humans $(1,2)$. Integrins link their extracellular ligands to intracellular focal adhesion complexes and cytoskeletal elements and function as dynamic, bidirectional signaling receptors (3). Cells often express more than one type of integrin complex, which can exist in either an active or inactive conformational state (4). Changes in the expression of different types of integrins provide a cell with a mechanism by which it can interact with and respond to the unique extracellular matrix (ECM) in its immediate environment (5). Since integrin function is critical for a variety of cellular processes, the variables mentioned above allow for a wide range of responses related to cell adhesion, motility, proliferation, differentiation, and morphogenesis (1).

The various $\alpha / \beta$ integrin heterodimers can be clustered into four families based on their ligand-binding characteristics (2). Members of the Leu-Asp-Val (LDV)-binding integrin family ( $\alpha 4 \beta 1, \alpha 4 \beta 7, \alpha 9 \beta 1, \alpha E \beta 7$, and the four members of the $\beta 2$ subfamily) recognize a structurally related acid motif sequence in their ligands. The $\beta 2$ integrin subfamily consists of the $\beta 2$ subunit (also termed CD18) in combination with one of four different $\alpha$ (CD11) subunits: $\alpha \mathrm{L}$ (CD11a), $\alpha \mathrm{M}$ (CD11b), $\alpha \mathrm{X}$ (CD11c), or $\alpha \mathrm{D}$ (CD11d). $\beta 2$ integrins and their ligands, consisting of various ECM proteins and immunoglobulin-type counter-receptors such as the intercellular adhesion molecules, have been intensely studied in circulating leukocytes and play an important role

Correspondence: G.T. Kitten, Departamento de Morfologia, ICB, UFMG, 30270-901 Belo Horizonte, MG, Brasil.

USA efax: +815-377-0222. E-mail: kitten@icb.ufmg.br

Received September 8, 2009. Accepted December 9, 2009. Available online January 11, 2010. Published January 11, 2010. 
in the immune-inflammatory response (6). $\beta 2$ integrin is essential for leukocyte binding to and transmigration through the endothelial cell layer (7). Leukocytes from genetically engineered mice, which lack $\beta 2$ integrin, do not adhere or transmigrate efficiently through the endothelium at sites of injury (8). Mutation or deletion of specific sites within either the extracellular or the cytoplasmic domains of $\beta 2$ integrin also leads to reduced levels of $\beta 2$ integrin expression and function (9). Similar deficiencies are observed in patients suffering from leukocyte adhesion deficiency-1 in which neutrophils displaying low levels of $\beta 2$ integrin expression fail to arrive at sites of injury (7).

Although $\beta 2$ integrin is often described as a "leukocytespecific integrin", or as being "expressed exclusively in hematopoietic cells" (10), and has been mainly studied in relation to its role during leukocyte adhesion and inflammatory responses (6), a few studies have shown that it is also expressed by other cell types such as human umbilical vein endothelial cells (HUVEC) (11), cancer cells (12) and bone marrow stromal stem cells (13). However, little is known about the function of $\beta 2$ integrin outside of its leukocyte-associated activities. While there have been numerous studies on integrins $\beta 1$ and $\beta 3$ and their associated alpha subunits in various tissues during development $(5,14)$, there have been very few studies addressing the expression or function of $\beta 2$ integrin during embryonic development. Chamoux et al. (15) described the specific expression of the $\beta 2$ integrin subunit in chromaffin cells during development of the fetal adrenal gland. These investigators postulated that $\beta 2$ integrin may play a role in the migration of neural crest-derived pheochromoblasts through the fetal adrenal cortex to the center of the gland, where they colonize and are important in the formation of the chromaffin cells within the adrenal medulla. A study in Xenopus embryos, in which the timing of appearance of various beta integrins was analyzed, noted that $\beta 2$ integrin was expressed at high levels in late tailbud stages, but its distribution was not determined (16).

Integrin-mediated cellular interactions are essential during embryogenesis, including cardiac morphogenesis (17-19). During the initial stages of cardiac development, the embryonic heart tube is composed of three layers: the external myocardium, the internal endothelial layer and the cardiac jelly, an acellular layer containing various types of ECM proteins (20-22). As development proceeds, the cardiac jelly expands to form endocardial cushions in the atrioventricular (AV) canal and outflow tract. Within the endocardial cushions, signals originating from the myocardium activate a subset of endothelial cells to undergo an epithelial-mesenchymal transformation (EMT) and migrate into the cardiac jelly (23). These mesenchymal cells acquire fibroblast-like characteristics and are responsible for synthesizing most of the connective tissue proteins in the valve leaflets and membranous portion of the interventricular septum (21).
Among the most common types of congenital heart defects are atrioventricular septal defects (AVSDs). Nearly $70 \%$ of all AVSDs are diagnosed in infants with trisomy 21 (Down syndrome) (24). This association has led to speculation that genes on chromosome 21 are important in $\mathrm{AV}$ valve development. Interestingly, the $\beta 2$ integrin gene locus has been mapped to the region on human chromosome 21, which has been linked to congenital heart defects (24), raising the possibility that it may play a role in AV valve morphogenesis. Therefore, the objective of the present study was to define the temporal and spatial distribution of $\beta 2$ integrin in the developing embryonic heart during cardiac morphogenesis. Results from PCR, in situ hybridization and immunolocalization studies have demonstrated that $\beta 2$ integrin and several of its $\alpha$ integrin partners are expressed by endothelial, mesenchymal, epicardial, and myocardial cells in both mouse and chicken embryonic hearts. These results indicate that $\beta 2$ integrin can be expressed by non-hematopoietic embryonic cells where it may mediate various morphogenetic events such as those which occur during cardiogenesis.

\section{Material and Methods}

\section{Embryos}

Swiss mice were allowed to mate and pregnancy was detected by the presence of a copulation plug. The appearance of the plug was designated as day 0.5 of gestation. Embryos were dissected from the pregnant females after the required period of gestation. Fertilized White Leghorn eggs were incubated at $38^{\circ} \mathrm{C}$ and the chicken embryos were collected at stages $\mathrm{HH} 10$ to $\mathrm{HH} 28$ (25). All protocols involving animals were reviewed and approved by the Ethics Committee for Animal Experimentation (CETEA) of the Federal University of Minas Gerais.

\section{Immunostaining and confocal microscopy}

Staged mouse embryos were dissected in phosphatebuffered saline (PBS), cryofixed and freeze-substituted in a $-70^{\circ} \mathrm{C}$ solution of $80 \%$ methanol $/ 20 \%$ dimethyl sulfoxide and then processed for cryostat sections. As a positive integrin beta control, the thymus from a 1-month-old mouse was collected and processed as above. Tissue sections were mounted on silane-coated slides and hydrated in $\mathrm{dH}_{2} \mathrm{O}$ followed by PBS. Nonspecific binding of antibodies was blocked using $1 \%$ bovine serum albumin (BSA), $0.1 \%$ Tween 20 in PBS for 1-2 $\mathrm{h}$ and followed by an overnight incubation at $4^{\circ} \mathrm{C}$ with primary antibodies. Affinity-purified polyclonal antibodies against specific integrin subunits were obtained from Santa Cruz Biotechnology, Inc. (USA): two different antibodies against $\beta 2$ integrin were used (sc6623, epitope at the C-terminus and sc-6625, epitope at the $\mathrm{N}$-terminus), as well as $\alpha \mathrm{L}$ (sc-15327), $\alpha \mathrm{M}$ (sc-6614) and $\alpha X$ (sc-26692). FITC-conjugated rabbit anti-goat IgG (Cappel Laboratories, USA), Cy3-conjugated donkey anti- 
goat, Cy3-conjugated goat anti-rabbit and Cy5-conjugated donkey anti-goat (Jackson Laboratory, USA) were used as secondary antibodies. Primary and secondary antibodies were diluted in $0.1 \%$ BSA/0.01\% Tween 20/PBS. After labeling with secondary antibodies for 1-2 $\mathrm{h}$ at room temperature, sections were washed in PBS and mounted in 10\% 1.0 $\mathrm{M}$ Tris- $\mathrm{HCl}, \mathrm{pH} \mathrm{9.0/90 \%} \mathrm{glycerol.} \mathrm{In} \mathrm{control} \mathrm{experiments,}$ primary antibodies were omitted from the staining protocol. Sections were analyzed using a laser scanning confocal microscope (Zeiss 510META, Germany).

We used fluorescent and hybrid routing protocols (HRP) to immunolocalize $\beta 2$ integrin in embryonic chicken hearts. Immunofluorescent staining methods for $\beta 1$ and $\beta 2$ integrins were the same as used for mouse tissues. For HRP experiments, staged chicken embryos were dissected in PBS, fixed in $4 \%$ paraformaldehyde, paraffin embedded and sectioned. Sections were deparaffinized and hydrated and antigen retrieval was performed using $0.1 \mathrm{M}$ citrate buffer, $\mathrm{pH} 5.5$, for $15 \mathrm{~min}$ in a microwave oven. Endogenous peroxidase activity was blocked by immersing slides in $3 \%$ hydrogen peroxide in methanol. Slides were blocked with $2 \%$ BSA, $0.1 \%$ Tween 20 in PBS and incubated with polyclonal antibodies against $\beta 2$ integrin (Santa Cruz Biotechnology, Inc., sc-6623 and sc-6625) as described above. Antibodies were diluted in $0.2 \%$ BSA, $0.01 \%$ Tween 20 in PBS. Sections were washed in PBS, incubated with HRP-conjugated secondary antibody at room temperature (Santa Cruz Biotechnology, Inc., sc-2020), and then washed again in PBS. Color reaction was carried out in the dark with $0.01 \%$ diaminobenzidine tetrahydrochloride and $0.03 \%$ $\mathrm{H}_{2} \mathrm{O}_{2}$ in PBS. In control experiments, primary antibodies were omitted from the staining protocol. Images were captured using a Leica microscope (Germany) equipped with Normarski Optics.

\section{Reverse transcriptase PCR (RT-PCR) and quantitative real-time PCR}

Total RNA was extracted from White Leghorn chicken embryonic tissues using Trizol (Gibco, USA). For PCR expression studies, whole hearts and $A V$ canal regions were microdissected from stage HH14-28 embryos. All samples were DNase treated (Ambion, USA) prior to reverse transcription using the iScript cDNA synthesis kit (Bio-Rad, USA). Samples were analyzed in a Nanodrop ND-100 analyzer (Thermo Fisher Scientific Inc., USA) and $1 \mu \mathrm{g}$ template was added per PCR assay following the manufacturer's instruction. cDNA was synthesized using Hot Start PCR with AmpliTaq Gold DNA polymerase (Applied Biosystems, USA). cDNA concentration was established with the QuantiiT Oligreen ssDNA reagent (Molecular Probes, USA) as described previously (26). Real-time PCR was performed with Platinum SYBR Green UDG (Invitrogen, USA) using $100 \mathrm{ng}$ cDNA per reaction under the following conditions: $50^{\circ} \mathrm{C}$ for $2 \mathrm{~min}, 95^{\circ} \mathrm{C}$ for $2 \mathrm{~min}$, and 35 cycles as follows: $94^{\circ} \mathrm{C}$ for $30 \mathrm{~s}, 58^{\circ} \mathrm{C}$ for $15 \mathrm{~s}$, and $72^{\circ} \mathrm{C}$ for $45 \mathrm{~s}$. A minimum of 3 different samples per stage were used and experiments were performed in triplicate for each sample. Primer pairs for each integrin subunit were designed using SciTools PrimerQuest (http://www.idtdna.com/Scitools/Applications/ Primerquest) and obtained commercially (Integrated DNA Technologies, USA). In order to avoid false results due to genomic DNA contamination, primers were designed to cross intron/exon boundaries. Separate forward and reverse primers for $\beta 2$ integrin were used in RT-PCR and real-time PCR experiments. RT-PCR conditions were $95^{\circ} \mathrm{C}$ for $10 \mathrm{~min}$ and 35 cycles as follows: $94^{\circ} \mathrm{C}$ for $30 \mathrm{~s}, 60^{\circ} \mathrm{C}$ for $30 \mathrm{~s}$, and $72^{\circ} \mathrm{C}$ for $45 \mathrm{~s}$. Control reactions for RT-PCR and real-time PCR were performed using primers for the 18 s ribosomal subunit. No-template control reactions were performed in every experiment. Additional controls, no enzyme and no primer, were also run in initial experiments (Table 1).

\section{In situ hybridization}

Sense and antisense avian $\beta 2$ integrin riboprobes corresponding to 387-1120 bp (GenBank NM_205251) were produced by RT-PCR from stage $\mathrm{HH} 20 \mathrm{AV}$ canal and subsequently cloned into pBlueScript II KS+ (Stratagene, USA). Sense (control) probe reactions were included in each experiment to determine the level of non-specific binding.

Whole-mount embryo in situ hybridization protocols

Table 1. List of real-time PCR and RT-PCR primers.

\begin{tabular}{lll}
\hline Primer & \multicolumn{1}{c}{ Forward } & \multicolumn{1}{c}{ Reverse } \\
\hline ITGB2 $^{\mathrm{a}}$ & 5'-CAATGATGAGGTCACCTTCAAA-3' & 5'-CAGTCACAGTCACAGATGCTGT-3' \\
ITGB2 $^{\mathrm{b}}$ & 5'-AATGAAGCAAGAGGGCAATGCGAC-3' & 5'-ACAGTCGCAGAAGGTGCCATAGAT-3' \\
ITGAL $^{\mathrm{b}}$ & 5'-TTCAGCCATCTGCCTATGACCACA-3' & 5'-TGAGTGTGGAGGAGGCCTTGATTT-3' \\
ITGAM $^{\mathrm{b}}$ & 5'-AGACAAAGAACAACACACGCAGGC-3' & 5'-TGAGATCGTCTTGGCAGATGCTGT-3' \\
ITGAX $^{\mathrm{b}}$ & 5'-AGACGAGTTGCAGAAGGCCAAGTA-3' & 5'-AGACCATCACTGTCCACACAGCTT-3' \\
18s $^{\mathrm{a}, \mathrm{b}}$ & 5'-ACTCAACACGGGAAACCTCA-3' & 5'-ATGCCAGAGTCTCGTTCGTT-3' \\
\hline
\end{tabular}

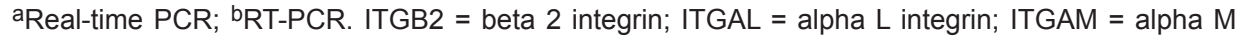
integrin; ITGAX = alpha $\mathrm{X}$ integrin; 18s = ribosomal subunit 18s. 
and digoxigenin-labeled riboprobe synthesis for chicken $\beta 2$ integrin probes were as described (27). Images of wholemount embryos were captured on a dissecting microscope (Leica model MZ125).

For in situ hybridization analysis on tissue sections, staged chicken embryos were collected in PBS, fixed overnight in a 6:3:1 mixture of ethanol/formalin/acetic acid, embedded in paraffin and sectioned. Sections were de-waxed, hydrated, proteinase $\mathrm{K}$ treated $(20 \mu \mathrm{g} / \mathrm{ml})$ and then post-fixed in $4 \%$ paraformaldehyde in PBS. Sections were incubated in pre-hybridization solution at $65^{\circ} \mathrm{C}$ prior to overnight incubation with hybridization solution containing a riboprobe at $65^{\circ} \mathrm{C}$. Slides were washed in SSC $/ 50 \%$ formamide $/ 0.1 \%$ Tween 20 at $65^{\circ} \mathrm{C}$, blocked in $20 \%$ sheep serum $/ \mathrm{MABT} / 2 \%$ blocking powder at room temperature and then incubated overnight with anti-digoxigenin antibody diluted in the same blocking solution at $4^{\circ} \mathrm{C}$. Slides were washed in MABT at room temperature and once in NTMT buffer prior to color reaction with NBT (Roche, USA) and $\mathrm{BCIP}$ (Roche) in NTMT at $37^{\circ} \mathrm{C}$. Images were captured using a Leica microscope equipped with Normarski Optics.

\section{Results}

\section{$\beta 2$ integrin expression in the developing mouse heart}

mRNA transcripts of $\beta 2$ integrin, as well as its $\alpha$ partners - $\alpha \mathrm{L}, \alpha \mathrm{M}$, and $\alpha \mathrm{X}$ integrins - were successfully amplified by RT-PCR using RNA extracted from embryonic day 13.5

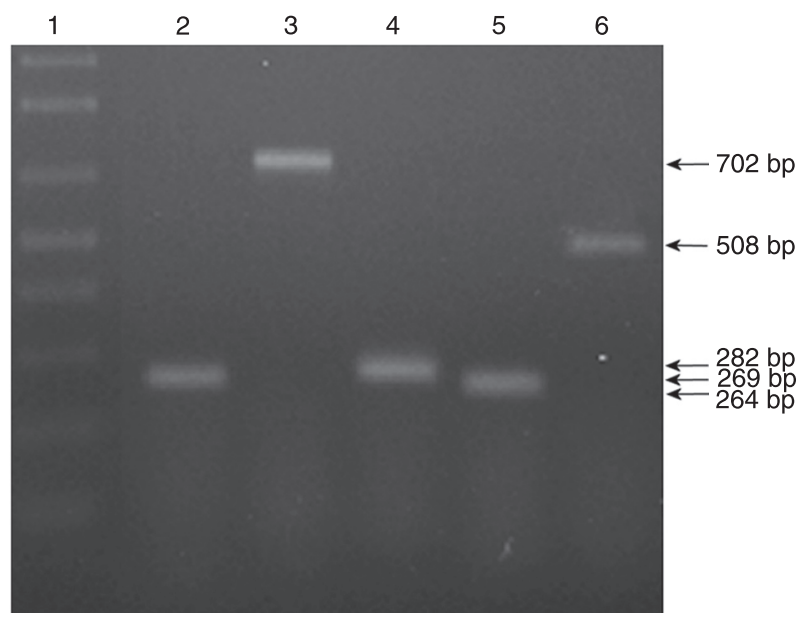

Figure 1. Detection of $\beta 2$ integrin and its $\alpha$ subunit partners in ED13.5 embryonic mouse hearts by RT-PCR. Integrin subunit expression was analyzed in ED13.5 embryonic mouse hearts by RT-PCR with specific primers: Lane 1, 1-kb DNA ladder; Lanes 2 and 3 , the presence of $\beta 2$ integrin was confirmed by using two different sets of primers, which generated the expected bands of 269 or 702 bp; Lane 4, aL (CD11a) 282 bp; Lane 5, aM (CD11b) 264 bp; Lane 6, aX (CD11c) 508 bp. No bands were detected in control reactions prepared without template, or reverse transcriptase, or primers (data not shown). ED = embryonic day.
(ED13.5) whole hearts (Figure 1). These results demonstrate that $\beta 2$ integrin mRNA is present in the embryonic heart, but do not rule out the possibility that it was derived from a small number of hematopoietic cells, which remain in the lumen of the hearts after the collection and washing procedures.

In order to determine which cells actually express $\beta 2$ integrin, we performed immunohistochemical localization experiments with two antibodies directed against different domains in $\beta 2$ integrin (i.e., $\mathrm{N}$ - or C-terminal epitopes). Positive control sections of 1-month-old mouse thymus incubated with either of these antibodies showed strong immunolabeling of thymocytes (Figure $2 \mathrm{H}$ ) as compared to secondary antibody control sections in which primary antibodies had been omitted from the incubation procedure (Figure $2 \mathrm{H}$, inset). $\beta 2$ integrin immunolabeling was performed in mouse embryos obtained from stages ED10.5 to 19.5. At ED10.5 and ED11.5, $\beta 2$ integrin immunostaining was observed in the endothelial layer of the cushions, on the surface of mesenchymal cells within the cardiac jelly, and in the epicardium (Figure 2A,B). At ED10, the epicardial layer had not yet completed its migration and covered the external surface of the myocardium. A low level of staining was also observed in some areas of the myocardium.

At ED13.5, when active mesenchymal cell migration is still occurring in the cushions, a strong signal was observed in the endothelium and mesenchymal cells (Figure 2C). At ED15.5, $\beta 2$ integrin signal decreased, but was still present in the valve endothelial cells and in mesenchymal cells, which were differentiating into the fibroblast-like, interstitial cells of the valve leaflets (Figure 2D). A similar pattern of $\beta 2$ integrin expression continued to be seen during AV valve maturation at ED17.5 (Figure 2E) but became weaker in valve endothelial cells and fibroblasts of the prenatal mouse AV valve at ED19.5 (Figure 2F). At ED15.5, the epicardium was strongly labeled and positive myocardial cells were observed in both the mural and trabecular portions of the myocardium (Figure $2 \mathrm{G}$ ). These observations show that $\beta 2$ integrin is expressed by non-hematopoietic cells during the early stages of mouse heart development, including in cells involved in the EMT, which occurs in the forming valves. Occasionally, intensely immunolabeled cells were seen within the lumen of the heart (Figure 2D-F), with specific staining well above background autofluorescence, indicating high levels of $\beta 2$ integrin expression. Although we have not characterized these cells, it is possible that they are hematopoietic cells, hemangioblasts, and/or endothelial progenitor cells, all of which are known to express $\beta 2$ integrin (28).

\section{Immunolocalization of the $\alpha$ integrin partners of $\beta 2$ integrin in embryonic mouse heart}

As described above, mRNA transcripts for $\alpha \mathrm{L}, \alpha M$, and $\alpha \mathrm{X}$ were shown to be present in the embryonic heart (see Figure 1). Immunohistochemical procedures using 

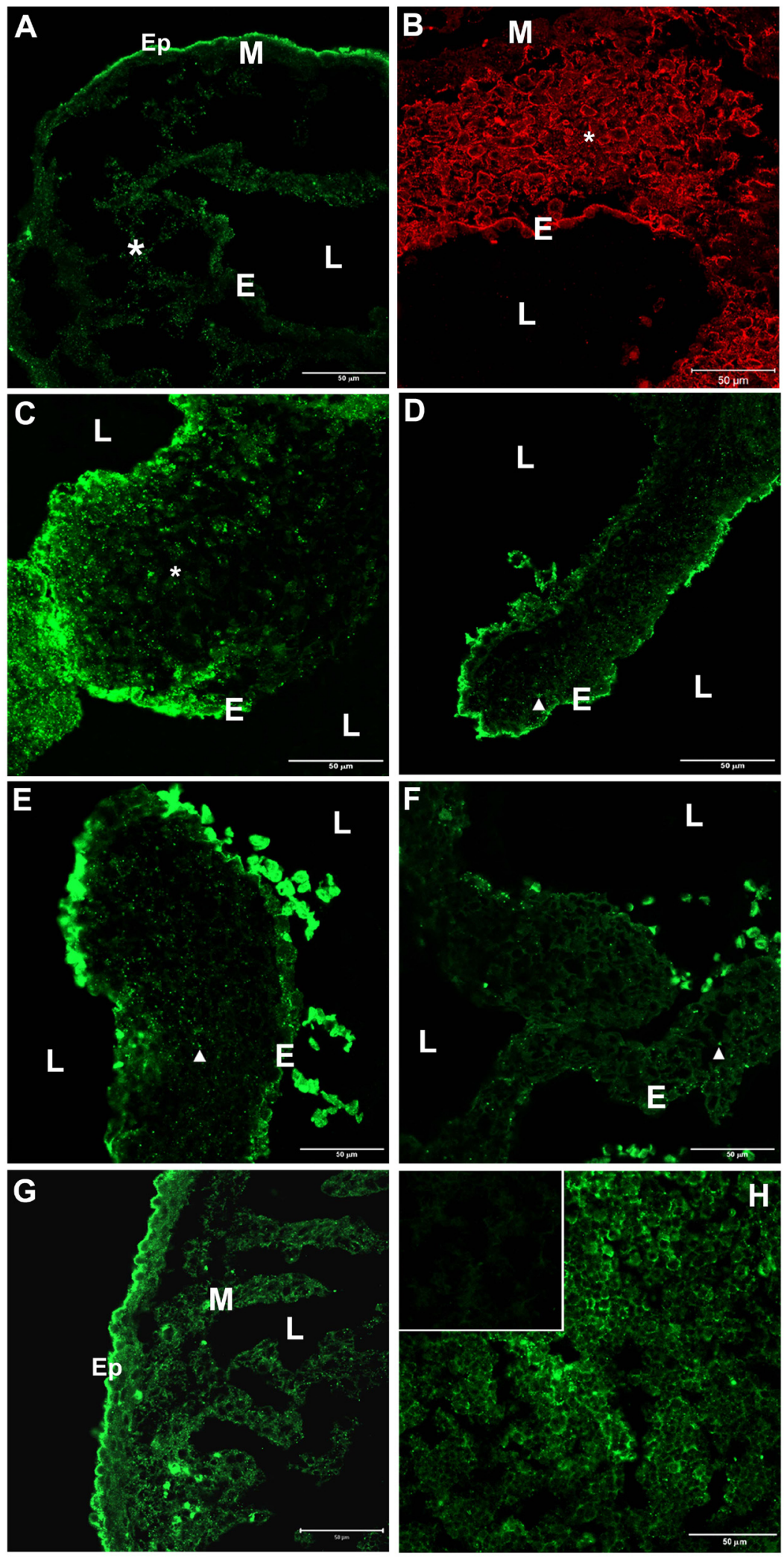

Figure 2. Immunofluorescent localization of $\beta 2$ integrin in mouse tissue. A-G, Sections of embryonic mouse hearts: $A$, ED10.5; $B$, ED11.5; $C$, ED13.5; $D$, ED15.5; $E$, ED17.5; F, ED19.5; G, ED15.5. Identical patterns of $\beta 2$ integrin immunostaining were obtained using the $\mathrm{N}$ - or $\mathrm{C}$-terminalspecific anti- $\beta 2$ integrin antibodies (data not shown). Secondary antibody control sections of embryonic hearts, which were included in every experiment, displayed no signal. $\beta 2$ was present in endothelium $(E)$, epicardium (Ep), myocardium (M), mesenchymal cells in the cardiac jelly $\left(^{*}\right)$, and fibroblast-like cells in valve leaflets (arrowheads). Immunolabeled myocardial cells were observed in both the mural and trabecular portions of the myocardium $(G)$. Intensely positive cells were occasionally seen within the lumen $(L)$ of the heart in some sections (D-F). These cells were not characterized, but may represent hematopoietic cells, hemangioblasts, or endothelial progenitor cells (see text). $H$, Sections of 1-month-old mouse thymus. $\beta 2$ integrin was localized on the cell surface of thymocytes. $H$ (inset), Control sections in which the primary antibody was omitted displayed only a low level of autofluorescence signal. ED = embryonic day. Magnification bars $=50 \mu \mathrm{m}$. 
antibodies specific for these $\alpha$ integrin subunits allowed us to determine more precisely their distribution pattern. Endothelial cells of the AV canal cushion, mesenchymal cells inside the cardiac jelly and myocardial cells expressed $\alpha \mathrm{L}$ integrin at ED11.5, during the initial stages of EMT (Figure 3A) and at ED13.5 (Figure 3B). Immunolabeling for $\alpha \mathrm{M}$ integrin displayed the same pattern as observed for $\alpha \mathrm{L}$ integrin in the AV canal at ED11.5 and ED13.5 (Figure $3 C, D)$. An antibody specific for $\alpha X$ integrin showed that it was also expressed in the AV canal at ED11.5 and ED13.5
(Figure 3E,F), but with slightly less reactivity in the myocardial layer. The positive results obtained with antibodies against the $\alpha \mathrm{L}, \alpha \mathrm{M}$ and $\alpha \mathrm{X}$ partners of $\beta 2$ integrin indicate that various $\alpha / \beta 2$ integrin heterodimers are present in the embryonic heart.

\section{$\beta 2$ integrin expression in developing avian embryos}

The distribution of $\beta 2$ integrin was not unique to mouse heart since we also confirmed expression in embryonic chicken heart. RNA from whole hearts and AV canal seg-
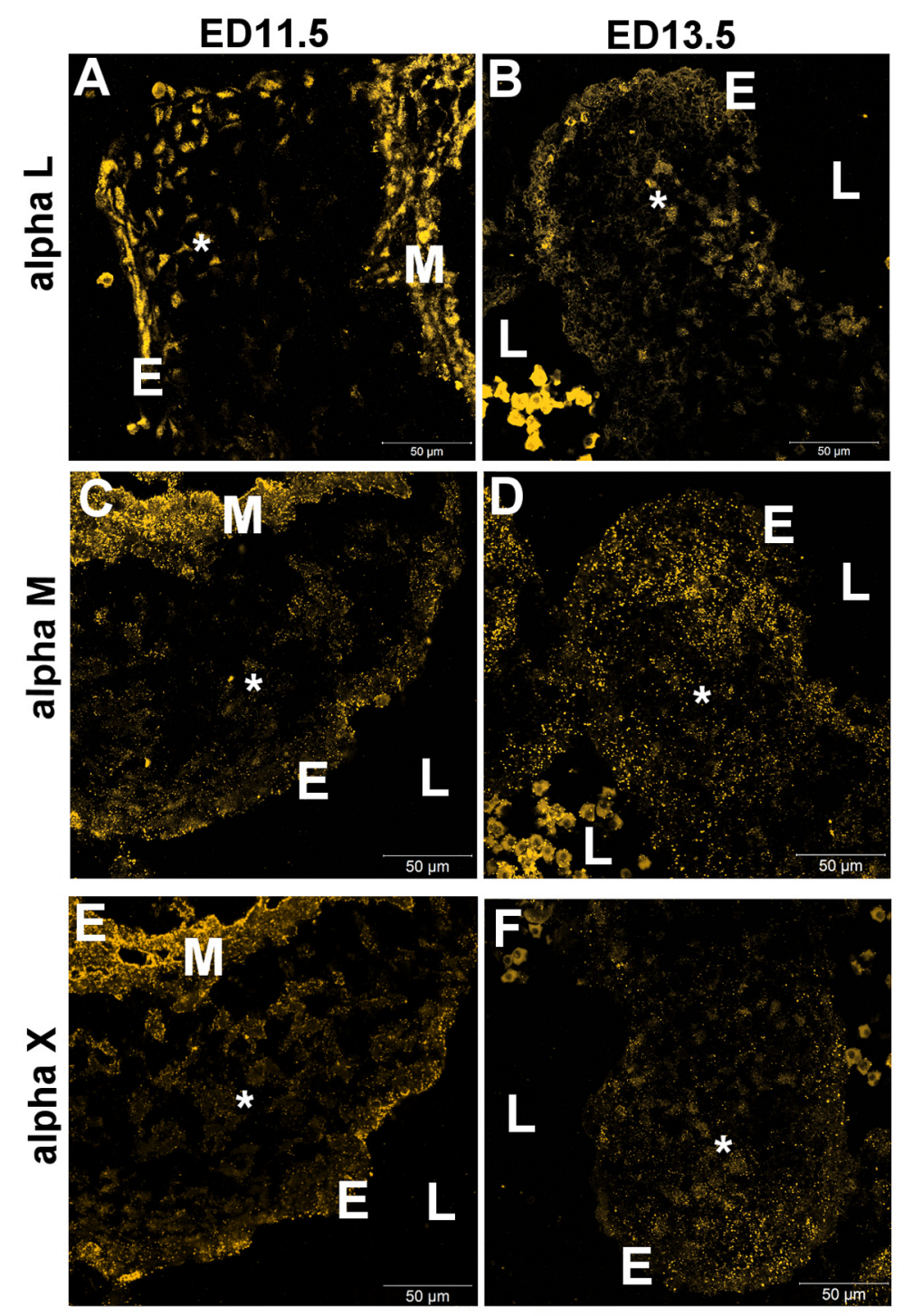

Figure 3. Immunofluorescent localization of the $\alpha$ integrin subunit partners of $\beta 2$ integrin in embryonic mouse hearts. Sections of $\operatorname{ED} 11.5(\mathrm{~A}, \mathrm{C}, \mathrm{E})$ and $\mathrm{ED} 13.5(\mathrm{~B}, \mathrm{D}, \mathrm{F})$ mouse hearts were immunolabeled with antibodies against specific $\alpha$ integrin subunits: $A, B, \alpha \mathrm{L}$ (CD11a); C,D, aM (CD11b); E, F, aX (CD11c). No immunostaining was observed in control sections in which the primary antibody was omitted (data not shown). Incubation of sections of mouse thymus with each of these a integrin antibodies (data not shown) displayed a similar staining pattern as observed with immunostaining of $\beta 2$ integrin (see Figure $2 G$ ). $E=$ endothelium; $L=$ lumen; $M=m y o c a r d i u m ;$ ${ }^{*}=$ mesenchymal or fibroblast-like cells in the forming valve leaflets. ED = embryonic day. Magnification bars $=50 \mu \mathrm{m}$. 
ments isolated a) at the onset of the EMT (HH14), b) during active mesenchymal cell invasion $(\mathrm{HH} 17-\mathrm{HH} 20)$, and $\mathrm{c}$ ) during endocardial cushion remodeling $(\mathrm{HH} 25$ and $\mathrm{HH} 28)$ were used as templates for RT-PCR and real-time PCR. $\beta 2$ integrin transcripts were expressed in all embryonic chick hearts and AV canal samples analyzed with RT-PCR (Figure $4 A, B)$. Results of RT-PCR experiments using the 18 s ribosomal subunit as a control displayed similar band densities in all of the stages tested (data not shown). Real-time PCR showed that cardiac $\beta 2$ integrin mRNA levels increase in

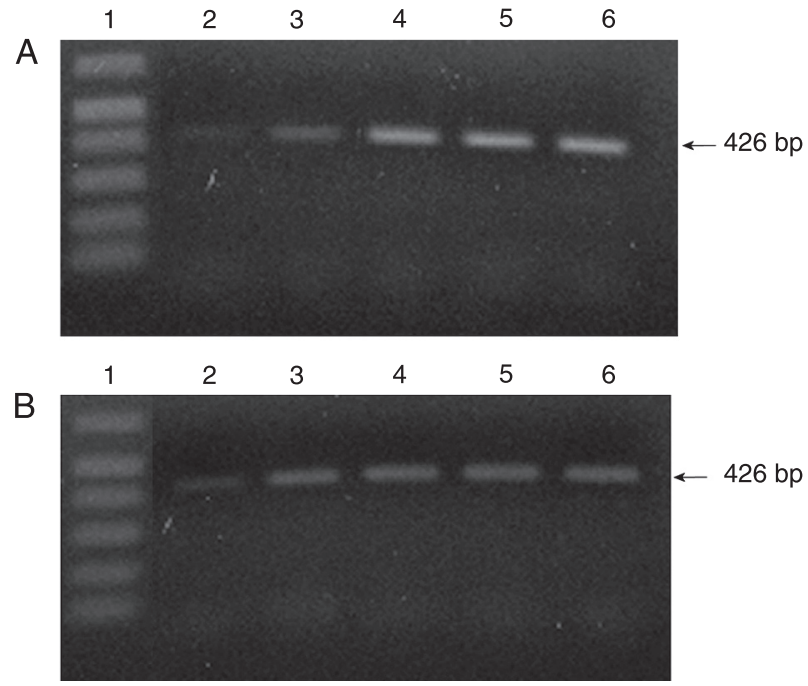

Figure 4. RT-PCR analysis of $\beta 2$ integrin in embryonic chicken hearts. RT-PCR analysis of $\beta 2$ integrin subunit expression was performed using total RNA isolated from whole embryonic chicken hearts (A) or dissected atrioventricular canal regions (B). Lane 1, 1-kb DNA ladder; lane 2, HH14; lane 3, $\mathrm{HH} 17$; lane 4, $\mathrm{HH} 20$; lane 5, $\mathrm{HH} 25$, and lane 6, $\mathrm{HH} 28$.

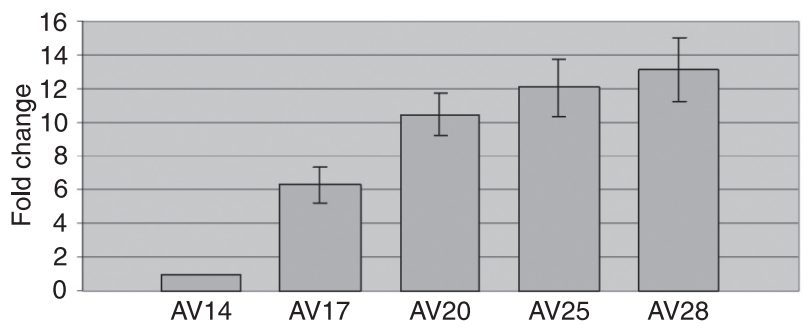

Figure 5. Relative quantitation of $\beta 2$ integrin expression in the chicken atrioventricular (AV) canal. mRNA was isolated from dissected AV canals at different stages of development and analyzed using real-time PCR. $\beta 2$ integrin mRNA was detectable at stage $\mathrm{HH} 14$, increased significantly at $\mathrm{HH} 17$, during the period when numerous mesenchymal cells are actively migrating in the endocardial cushions, and progressively increased in subsequent stages. mRNA fold changes were calculated relative to the values obtained for HH14. Data are reported as means \pm SEM for three experiments. the AV canal during the remodeling of endocardial cushion EMT and subsequent remodeling of the valves (Figure 5). Real-time PCR controls with 18 s showed equal levels in all stages (data not shown).

In situ hybridization protocols were performed on whole mounts and sections of chicken embryos to define the spatial distribution of $\beta 2$ integrin mRNA transcripts during endocardial cushion EMT and AV valve remodeling. At $\mathrm{HH} 14$, $\beta 2$ integrin was expressed in the cardiac myocardium and endocardium (Figure 6A,C). At HH20, 32 integrin mRNA was detected in a more pronounced manner in the myocardium, epicardium and endocardium, and was expressed in mesenchymal cells invading the endocardial cushions (Figure 6B,D). At $\mathrm{HH} 25$ and $\mathrm{HH} 28$, when the cushions are heavily populated by mesenchymal cells, $\beta 2$ integrin continued to be detected clearly in the endothelial layer,
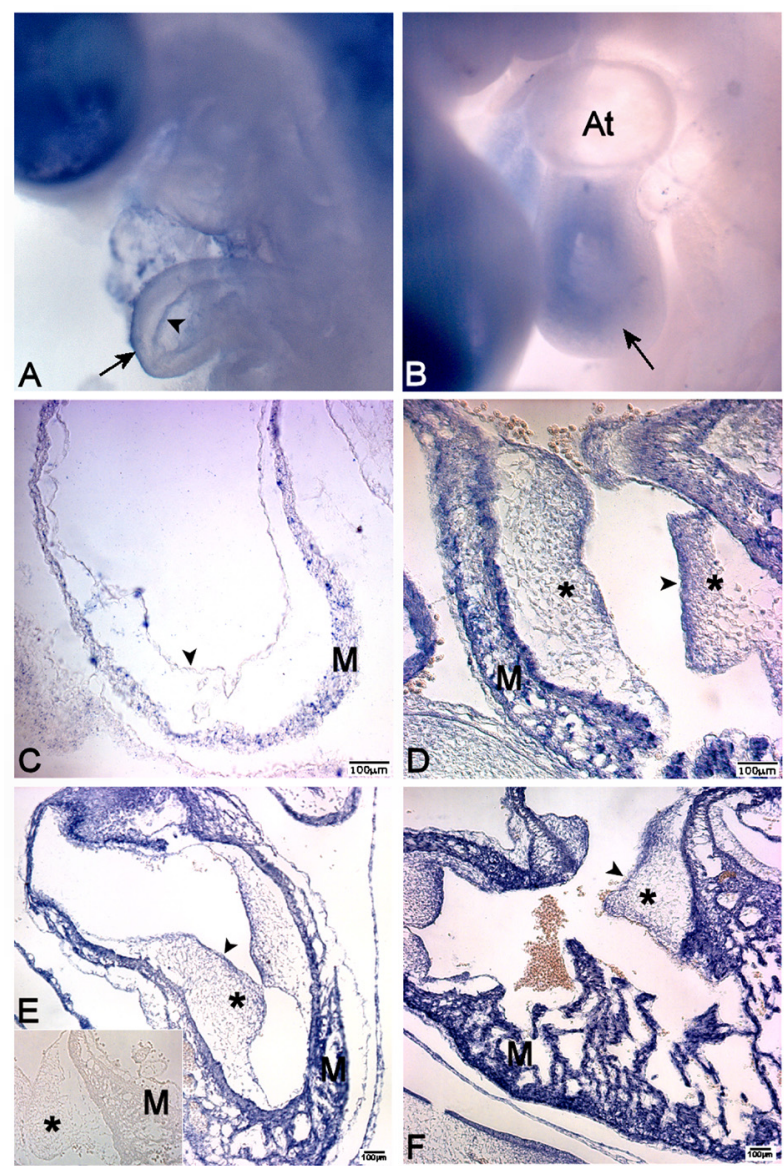

Figure 6. Localization of $\beta 2$ integrin mRNA in chicken embryos using in situ hybridization. Positive labeling of $\beta 2$ integrin mRNA was detected in whole mounts $(A, B)$ and sections $(C-F)$ of embryonic chicken hearts using an antisense riboprobe. $A, C, \mathrm{HH} 14$; $B, D, \mathrm{HH} 20 ; E, \mathrm{HH} 25$, and $F, \mathrm{HH} 28$. $E$ (inset), Control in which $\mathrm{HH} 25$ showed no labeling with a sense probe for $\beta 2$ integrin. At = atrium; $\mathrm{M}=$ myocardium; * = mesenchymal cells; arrows = heart; arrowheads $=$ endothelium. Magnification bars $=100 \mu \mathrm{m}$. 
mesenchymal cells, epicardium, and myocardium (Figure $6 E, F)$. Control sections hybridized with $\beta 2$ integrin sense probe were negative (Figure $6 \mathrm{E}$, inset).

Immunohistochemical studies using HRP-conjugated secondary antibodies were also performed in the developing chick. At HH14 $\beta 2$ integrin staining was localized in the endothelium and the myocardium (Figure 7A,B). At $\mathrm{HH} 20$, $\beta 2$ integrin staining was more pronounced and was detected in endothelial layer, mesenchymal cells, epicardium, and myocardium (Figure 7C,D), matching the distribution pattern seen with in situ hybridization. As described by others (18), $\beta 1$ integrin was also present in the cardiac endothelium, myocardium and mesenchymal cells of the embryonic chicken heart (Figure 8).
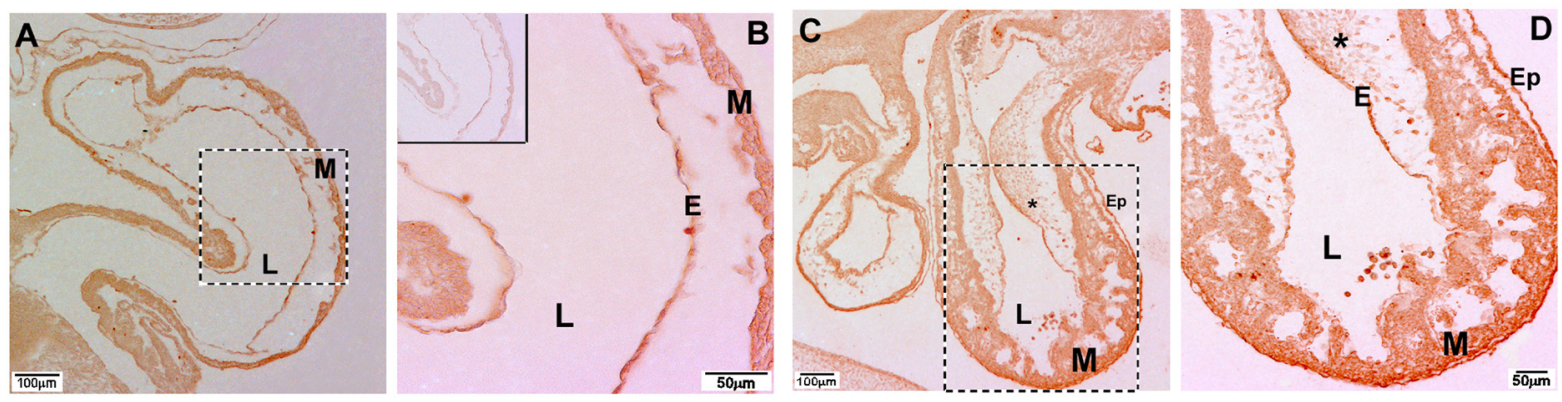

Figure 7. Immunohistochemical localization of $\beta 2$ integrin in embryonic chicken hearts. $A$, Positive immunolabeling for $\beta 2$ integrin was detected in the endothelial and myocardial layers of stage $\mathrm{HH} 14$ chicken heart. $B$, Higher magnification of the boxed area in $A$. $C, \beta 2$ integrin was present in the endothelium, mesenchymal cells, epicardium, and myocardium at $\mathrm{HH} 20$. $D$, Higher magnification of the boxed area in $C$. $B$ (inset), Control section adjacent to that seen in $A$ showing no reaction when the primary antibody was omitted. $E=$ endothelium; $\mathrm{Ep}=$ epicardium; $\mathrm{L}=$ lumen; $\mathrm{M}=$ myocardium; * = mesenchymal cells. Magnification bars: $A, C=100 \mu \mathrm{m} ; B, D=50 \mu \mathrm{m}$.
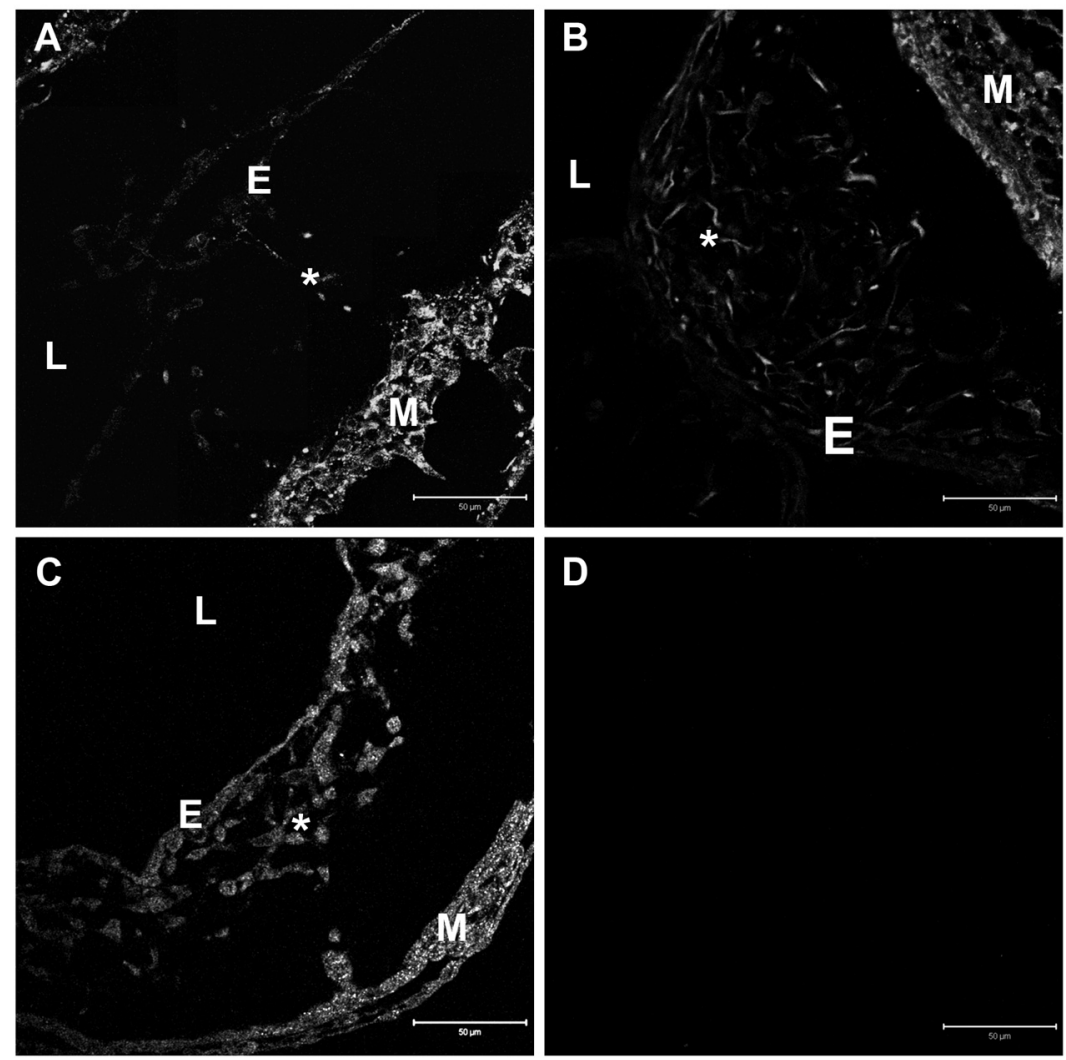

Figure 8. Immunofluorescent localization of $\beta 2$ and $\beta 1$ integrins in embryonic chicken heart. Immunostaining using Cy3-conjugated secondary antibodies. Sections of stages $\mathrm{HH}_{17}(\mathrm{~A})$ and $\mathrm{HH} 20(\mathrm{~B})$ chicken hearts showing $\beta 2$ integrin localization. $C, \beta 1$ integrin in stage $\mathrm{HH} 20$ heart. $D$, No staining was detected when the primary antibody was omitted from the staining protocol. $E=$ endothelium; $\mathrm{L}=$ lumen; $\mathrm{M}=$ myocardium; ${ }^{*}=$ mesenchymal cells. Magnification bars $=50 \mu \mathrm{m}$. 


\section{Discussion}

The spatial and temporal distribution and multiple binding functions of integrins have been intensely studied since the earliest reports characterizing these matrix receptors appeared in the literature (1). The fact that integrins play important roles in numerous cellular processes such as migration, adhesion, and signal transduction, as well as in morphogenesis and pathological process, continues to make them a focal point in research. A number of integrins have been characterized in the developing heart $(18,19)$. The $\beta 2$ integrin subfamily has been extensively studied, but most of this research centers on its role in the adhesion, migration and diapedesis of lymphocytes and leukocytes (6). Although the $\beta 2$ integrin family is frequently referred to as being "leukocyte specific" (10), in the present study, using PCR, in situ hybridization, and immunohistochemical methods, we demonstrate that $\beta 2$ integrin is also expressed by endothelial, mesenchymal, epicardial, and myocardial cells during normal heart development in both mammalian and avian embryos. It is noteworthy that three different alpha integrin partners for $\beta 2$ integrin (i.e., $\alpha \mathrm{L}, \alpha \mathrm{M}$, and $\alpha \mathrm{X}$ ) were also detected during heart formation. The functional importance of each of these integrin $\alpha / \beta 2$ combinations during the process of cardiogenesis remains to be determined.

The functional role of $\beta 2$ integrin has been studied in $\beta 2$ integrin null mice (29). These mice are viable and do not have any grossly obvious abnormalities in the heart or any other organs, but do display a phenotype closely resembling that of leukocyte adhesion deficiency type 1 patients, including leukocytosis, impaired leukocyte adhesion and migration, and the occurrence of mucocutaneous infections. However, it is important to note that in this study, the number of homozygous mice was lower than predicted by Mendelian genetics, suggesting that some $\beta 2$ null offspring die prenatally. In addition, $10-40 \%$ of newborn $\beta 2$ null animals were reported to die perinatally due to unreported causes. Previous studies have shown that $\beta 1$, and possibly other $\beta$ integrins, are able to compensate, at least partially, for the loss of $\beta 2$ integrin (30). Such compensatory mechanisms may allow some of the $\beta 2$ null embryos to develop into adults. Other studies have shown that $\beta 2$ null mice often have additional defects. For example, Miura et al. (13) reported that $\beta 2$ null mice display certain features of osteoporosis, including decreased bone mineral density and increased trabecular bone space. Thus, based on the results presented here, a detailed morphometric analysis of the hearts of $\beta 2$ null mice is warranted.

To our knowledge, there have been relatively few other studies demonstrating the presence of $\beta 2$ integrin in developing tissues. The presence of high levels of $\beta 2$ integrin mRNA was noted in the late tailbud stage of Xenopus embryos, but specific tissue distribution was not determined (16). A study of ECM components and their integrin receptors in the human fetal adrenal gland demonstrated that $\beta 2$ integrin is expressed by neural crest-derived chromaffin cells, which migrate through the fetal cortex on their way to the center of the gland, where they colonize and help form the medulla (15). Whether $\beta 2$ integrin is expressed by neural crest cells in other locations during development has not been reported. Several other studies have shown that $\beta 2$ integrin is also expressed in cell types other than leukocytes, such as HUVEC and cancer cells $(11,12)$. Although it is clear that a number of non-hematopoietic cells can express $\beta 2$ integrin, little is known about the function of $\beta 2$ integrin outside its leukocyte-associated activities.

The ligands, which bind to $\beta 2$ integrin and its $\alpha$ partners in the embryonic heart, have not yet been determined. The $\beta 2 / \alpha$ heterodimers may interact with counter-receptors (eg., VCAM, ICAM) on adjacent cells and thus modulate cell-cell adhesion, or bind to ECM proteins. $\beta 2$ integrins have been shown to bind to various ECM proteins, including collagens, fibronectin, fibrinogen, plasminogen, and heparin (2). Collagens, fibronectin and numerous other matrix proteins are present in most embryonic tissues, including the cardiac jelly $(20,21,31-33)$. Interestingly, $\beta 2$ integrins also bind to CCN1 (CYR61), a secreted, cysteine-rich protein associated with the ECM that promotes cell adhesion, migration, proliferation, differentiation, and survival or death in a cell type-dependent manner (34). CCN1 is expressed in the endothelium, cushion mesenchymal cells and myocardium, and is thought to be essential for tissue remodeling during cardiac development. Ccn1 null mice suffer embryonic lethality and display impaired cardiac valvuloseptal morphogenesis, which results in AVSDs (35). Ccn1 deficiency does not affect endocardial cushion tissue formation or EMT, but results in accelerated apoptosis in cushion tissue and reduced gelatinous activity in the ventricular septum and $\mathrm{AV}$ valves.

The expression of $\beta 2$ integrin within the embryonic heart during the period when the AV valves are still forming is especially relevant when one considers that the gene for $\beta 2$ integrin is localized in the region of chromosome 21 associated with congenital heart defects (24). Approximately $40 \%$ of trisomy $21 /$ Down syndrome patients have congenital heart defects, the majority of which involve AVSDs. It is known that leukocytes and thymocytes from Down syndrome patients overexpress $\beta 2$ integrin, which may affect immune defense in these patients (36). The effect an increase in $\beta 2$ integrin expression would have within the developing heart is unknown. When expressed at low levels in cell lines, $\beta 2$ integrin cooperates with $\beta 1$ integrins to support cell migration (37). Conversely, increased expression of $\beta 2$ integrin results in increased cell adhesiveness and inhibition of cell migration. In this system, $\beta 2$ integrin appears to act as a brake: the higher the level of expression, the stronger the brake becomes until migration is finally stopped. It will be of interest to determine if $\beta 2$ integrin functions in a similar manner in the embryonic heart. Many of the observations cited above support the idea that $\beta 2$ integrin is functioning 
during the migration of the cushion tissue mesenchyme, but it is important to remember that $\beta 2$ integrin is also expressed in the epicardium and myocardium during heart development. Additional studies will be needed in order to clarify the functional importance of $\beta 2$ integrin in each of these locations during cardiac morphogenesis.

\section{Acknowledgments}

The authors thank Lorenza Carvalhaes, Othon Gervásio and André Tavares for their comments and help with the initial immunolocalization studies and for the use of the Zeiss 510 Meta confocal microscope at the Center of Electron Microscopy (CEMEL), ICB-UFMG. The authors also thank Christopher Kushmerick (Federal University of Minas Gerais) for editing the text. L.A.M. Oliveira was supported by fellowships from the Brazilian research funding agencies CNPq and CAPES. This manuscript fulfills part of the requirements necessary for his doctoral degree. R.K. Baker and S.E. Klewer are recipients of fellowships from CNPq, CAPES, and NIH R01 HL074070. Publication costs paid by FAPEMIG.

\section{References}

1. Hynes RO. Integrins: bidirectional, allosteric signaling machines. Cell 2002; 110: 673-687.

2. Humphries JD, Byron A, Humphries MJ. Integrin ligands at a glance. J Cell Sci 2006; 119: 3901-3903.

3. Harburger DS, Calderwood DA. Integrin signalling at a glance. J Cell Sci 2009; 122: 159-163.

4. Arnaout MA, Goodman SL, Xiong JP. Structure and mechanics of integrin-based cell adhesion. Curr Opin Cell Biol 2007; 19: 495-507.

5. Meighan CM, Schwarzbauer JE. Temporal and spatial regulation of integrins during development. Curr Opin Cell Biol 2008; 20: 520-524.

6. Springer TA. Traffic signals for lymphocyte recirculation and leukocyte emigration: the multistep paradigm. Cell 1994; 76 : 301-314.

7. Hogg N, Bates PA. Genetic analysis of integrin function in man: LAD-1 and other syndromes. Matrix Biol 2000; 19: 211-222.

8. Palazzo AJ, Jones SP, Girod WG, Anderson DC, Granger $D N$, Lefer DJ. Myocardial ischemia-reperfusion injury in CD18- and ICAM-1-deficient mice. Am J Physiol 1998; 275: $\mathrm{H} 2300-\mathrm{H} 2307$.

9. Tan SM, Hyland RH, Al-Shamkhani A, Douglass WA, Shaw JM, Law SK. Effect of integrin beta 2 subunit truncations on LFA-1 (CD11a/CD18) and Mac-1 (CD11b/CD18) assembly, surface expression, and function. J Immunol 2000; 165: 2574-2581.

10. Hogg N, Henderson R, Leitinger B, McDowall A, Porter J, Stanley P. Mechanisms contributing to the activity of integrins on leukocytes. Immunol Rev 2002; 186: 164-171.

11. Langeggen $H$, Berge KE, Johnson E, Hetland G. Human umbilical vein endothelial cells express complement receptor 1 (CD35) and complement receptor 4 (CD11c/CD18) in vitro. Inflammation 2002; 26: 103-110.

12. Karmakar S, Mukherjee R. Integrin receptors and ECM proteins involved in preferential adhesion of colon carcinoma cells to lung cells. Cancer Lett 2003; 196: 217-227.

13. Miura Y, Miura M, Gronthos S, Allen MR, Cao C, Uveges $T E$, et al. Defective osteogenesis of the stromal stem cells predisposes CD18null mice to osteoporosis. Proc Natl Acad Sci U S A 2005; 102: 14022-14027.

14. Bokel C, Brown NH. Integrins in development: moving on, responding to, and sticking to the extracellular matrix. Dev Cell 2002; 3: 311-321.
15. Chamoux E, Bolduc L, Lehoux JG, Gallo-Payet N. Identification of extracellular matrix components and their integrin receptors in the human fetal adrenal gland. J Clin Endocrinol Metab 2001; 86: 2090-2098.

16. Ransom DG, Hens MD, DeSimone DW. Integrin expression in early amphibian embryos: cDNA cloning and characterization of Xenopus beta 1, beta 2, beta 3 , and beta 6 subunits. Dev Biol 1993; 160: 265-275.

17. Clark EB, Markwald RR, Takao A, Hamilton RM. Developmental mechanisms of heart disease. New York: Futura; 1995.

18. Simpson DG, Reaves TA, Shih D, Burgess W, Borg TK, Terracio L. Cardiac integrins: The ties that bind. Cardiovasc Pathol 1998; 7: 135-143.

19. Danen $E H$, Sonnenberg A. Integrins in regulation of tissue development and function. J Pathol 2003; 200: 471-480.

20. Kitten GT, Markwald RR, Bolender DL. Distribution of basement membrane antigens in cryopreserved early embryonic hearts. Anat Rec 1987; 217: 379-390.

21. Little CD, Rongish BJ. The extracellular matrix during heart development. Experientia 1995; 51: 873-882.

22. Peacock JD, Lu Y, Koch M, Kadler KE, Lincoln J. Temporal and spatial expression of collagens during murine atrioventricular heart valve development and maintenance. Dev Dyn 2008; 237: 3051-3058.

23. Person AD, Klewer SE, Runyan RB. Cell biology of cardiac cushion development. Int Rev Cytol 2005; 243: 287-335.

24. Korenberg JR, Bradley C, Disteche CM. Down syndrome: molecular mapping of the congenital heart disease and duodenal stenosis. Am J Hum Genet 1992; 50: 294-302.

25. Hamburger V, Hamilton HL. A series of normal stages in the development of the chick embryo. J Morphol 1951; 88: 4992.

26. Tavares AL, Mercado-Pimentel ME, Runyan RB, Kitten GT. TGF beta-mediated RhoA expression is necessary for epithelial-mesenchymal transition in the embryonic chick heart. Dev Dyn 2006; 235: 1589-1598.

27. Nieto MA, Patel K, Wilkinson DG. In situ hybridization analysis of chick embryos in whole mount and tissue sections. Methods Cell Biol 1996; 51: 219-235.

28. Chavakis E, Aicher A, Heeschen C, Sasaki K, Kaiser R, El Makhfi N, et al. Role of beta2-integrins for homing and neovascularization capacity of endothelial progenitor cells. J Exp Med 2005; 201: 63-72. 
29. Scharffetter-Kochanek K, Lu H, Norman K, van Nood N, Munoz F, Grabbe S, et al. Spontaneous skin ulceration and defective T cell function in CD18 null mice. J Exp Med 1998; 188: 119-131.

30. Henderson RB, Lim LH, Tessier PA, Gavins FN, Mathies M, Perretti $M$, et al. The use of lymphocyte function-associated antigen (LFA)-1-deficient mice to determine the role of LFA1 , Mac-1, and alpha4 integrin in the inflammatory response of neutrophils. J Exp Med 2001; 194: 219-226.

31. Klewer SE, Krob SL, Kolker SJ, Kitten GT. Expression of type $\mathrm{VI}$ collagen in the developing mouse heart. Dev Dyn 1998; 211: 248-255.

32. Gittenberger-de Groot AC, Bartram U, Oosthoek PW, Bartelings MM, Hogers B, Poelmann RE, et al. Collagen type $\mathrm{VI}$ expression during cardiac development and in human fetuses with trisomy 21. Anat Rec A Discov Mol Cell Evol Biol 2003; 275: 1109-1116.

33. Carvalhaes LS, Gervasio OL, Guatimosim C, Heljasvaara R,
Sormunen R, Pihlajaniemi T, et al. Collagen XVIII/endostatin is associated with the epithelial-mesenchymal transformation in the atrioventricular valves during cardiac development. Dev Dyn 2006; 235: 132-142.

34. Chen CC, Lau LF. Functions and mechanisms of action of CCN matricellular proteins. Int J Biochem Cell Biol 2009; 41: 771-783.

35. Mo FE, Lau LF. The matricellular protein CCN1 is essential for cardiac development. Circ Res 2006; 99: 961-969.

36. Murphy M, Insoft RM, Pike-Nobile L, Derbin KS, Epstein LB. Overexpression of LFA-1 and ICAM-1 in Down syndrome thymus. Implications for abnormal thymocyte maturation. $J$ Immunol 1993; 150: 5696-5703.

37. Yakubenko VP, Belevych N, Mishchuk D, Schurin A, Lam SC, Ugarova TP. The role of integrin alpha D beta2 (CD11d/ CD18) in monocyte/macrophage migration. Exp Cell Res 2008; 314: 2569-2578. 